\section{Abrasive Cytology for Isolating Mucosal Pathogens During Routine Endoscopy: GIUM Method}

Endoscopic access to the digestive tract may provide a good opportunity to isolate pathogens in patients in whom there is a clinical suspicion of digestive tract infection, and in immunosuppressive diseases. We have developed a method of transendoscopic abrasive cytology based on a metallic device, $23 \mathrm{~mm}$ in diameter and ovoid in shape, similar to a balloon, registered by its manufacturer under the name GIUM (from the Spanish for "stainless balloon for medical purposes") (Figure 1). Using this instrument, an extensive area of the digestive mucosa can be scanned, providing abundant cytological samples and tissue fragments (epithelium and stroma).

In 75 patents studied using this method, there was clinical suspicion of digestive tract infection in 63 patients (group A): diarrhea, esophagitis with plaque, parasitosis, and gastropathy associated with Helicobacter pylori infection. Group B consisted of 12 HIV-positive patients with clinical disease and digestive tract symptoms. In group A, samples were taken according to clinical suspicion, and in group B, samples were taken from the esophagus, stomach, second part of the duodenum, and rectosigmoid junction in all cases. In this group, biopsies were also taken from the second part of the duodenum.

In the patients in group A, 14 Candida and one Aspergillus species were isolated from the esophagus, there were 32 cases of Helicobacter pylori from the stomach, and one ameba was identified from the rectosigmoid junction. A total of 48 pathogens were isolated in these 63 patients.

In the patients in group B, five Candida species were isolated from the esophagus, there was one case of Helicobacter pylori in the stomach, three of Giardia, one Cryptosporidium, one Mycobacterium avium-intracellulare (Figure 2), two Isospora, one Microsporida, one parasite egg from the second part of the duodenum, and one Isospora from the rectosigmoid junction $(1,2)$. It was possible to isolate one or more pathogen from every patient in this group.

All of the pathogens were identified by the usual cytological staining procedures (3)

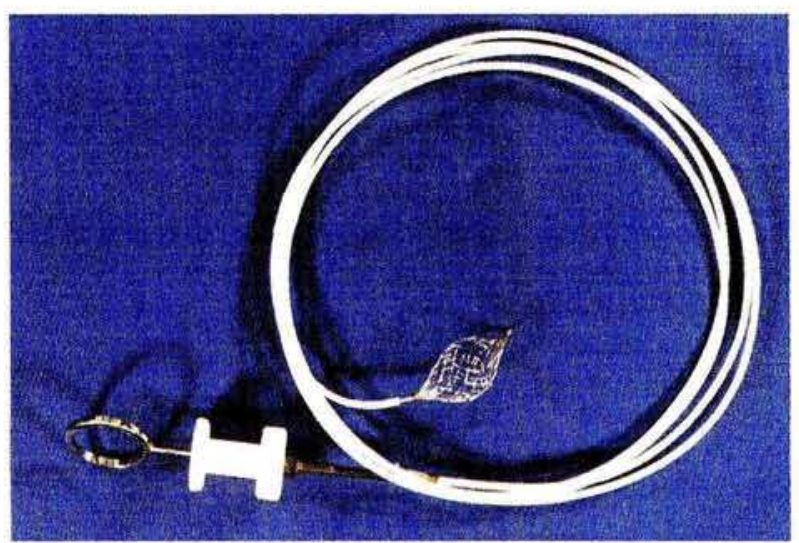

Figure 1: The GIUM device.

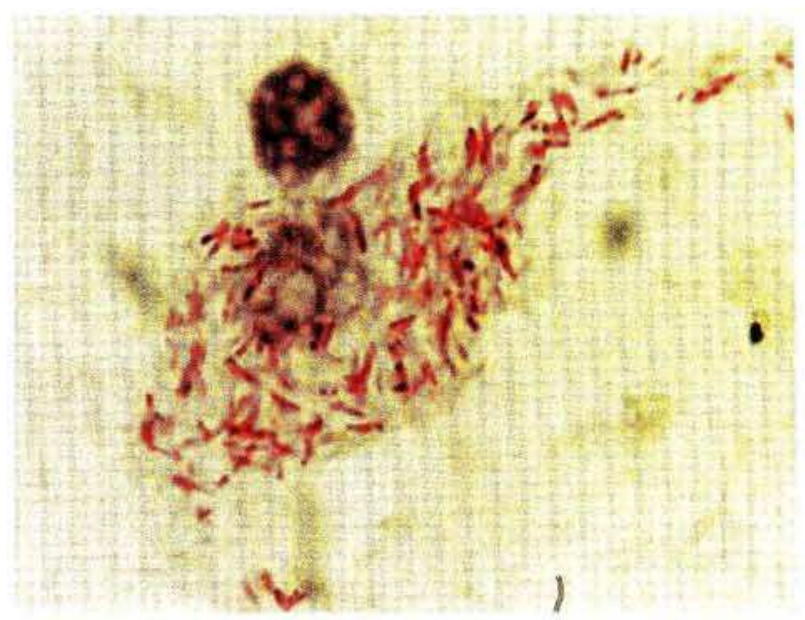

Figure 2: GIUM cytology from the second part of the duodenum, showing a vacuolated macrophage with multiple mycobacteria.

less than one hour after the sample had been obtained in the endoscopy room. Only one patient was found to have more significant findings than erythema of the mucosa at the endoscopic examination (multiple duodenal maculae, in the patient with Mycobacterium avium-intracellulare). At duodenal biopsy in group B, it was only possible to isolate two cases of Giardia infection, one of Strongyloides, and one of Cryptosporidium. This was probably due to the prior extensive contact of the GIUM with the mucosa in the abrasive technique.

Growing experience with this rapid identification method has made it possible to incorporate new aspects that can complement routine endoscopic diagnosis.

\section{Casco, D. Martins, S. Lettieri,}

H. W. Rubio

Gastroenterology Service,

Paroissien Hospital, La Matanza,

Buenos Aires, Argentina

\section{References}

1. Murty A, Luthra U, Sehgal K, Sodhani P. Cytologic detection of Strongyloides stercoralis in a routine cervicovaginal smear: a case report. Acta Cytol 1994; 38: $323-5$.

2. Muñoz E, Carmona T, Chaves F, et al. Identification of Giardia lamblia by gastric brush cytology. Acta Cytol 1996; 40: 1331-2.

3. Koneman EW, Allien S, Janda W, et al. Parasitology. In: Koneman EW, editor. Color atlas and textbook of diagnostic microbiology. 5 th ed. Philadelphia: Lippincott, 1997: 1093-9.

Corresponding Author

H. W. Rubio, M.D.

Montevideo 1738 PB

1021 Capital Federal

Buenos Aires, Argentina

Fax: +54-1-813-7158 